\title{
Salud en prisiones: el impacto de la reincidencia más allá de las enfermedades
}

\author{
Health in prisons: the impact of recidivism beyond diseases
}

\author{
Alvaro-J Idrovo ${ }^{1}$
}

Forma de citar: Idrovo, AJ. Salud en prisiones: el impacto de la reincidencia más allá de las enfermedades. Rev Univ Ind Santander Salud. 50(2): 104-105. doi: http://dx.doi.org/10.18273/revsal.v50n2-2018001 @c] (1)

En este número se presenta un importante aporte sobre la conceptualización de la reincidencia criminal y su impacto en el sistema penitenciario colombiano ${ }^{1}$, que resulta ser un ejemplo de los contextos complejos donde la salud manifiesta su interconexión con otros ámbitos de la vida humana. Tradicionalmente se reconocen las prisiones y demás centros de reclusión como lugares facilitadores para la propagación de enfermedades infecciosas, entre las que sobresalen la hepatitis $\mathrm{C}$, la tuberculosis, y el sida ${ }^{2}$. También resulta ser un tema conocido en estos contextos el problema de salud mental entre prisioneros ${ }^{3}$. Sin embargo, más allá de las enfermedades, existen otras problemáticas más silentes para quienes limitan el concepto de salud a sus manifestaciones biomédicas ${ }^{4}$. En lugares, como las prisiones, donde se muestran con gran intensidad los determinantes de la salud, es importante mantener una visión amplia que permita ver sus relaciones con los diversos tipos de violencia y los problemas de seguridad, la drogadicción, entre otros.

En relación con el delito se pueden considerar dos momentos de prevención importantes; el anterior a su ocurrencia (resiliencia) y el que se presenta como oportunidad mientras la persona está privada de su libertad, en proceso de resocialización, previniendo la reincidencia. Desde las ciencias de la salud, Colombia tiene una historia importante en el estudio de los factores asociados con la resiliencia frente a la delincuencia ${ }^{5,6}$, que han permitido definir políticas enfocadas a los jóvenes con riesgo de delinquir. Más recientemente, como consecuencia de la mayor capacidad académica entre los encargados de los centros carcelarios y penitenciarios, y el involucramiento de las universidades se vislumbra una época próxima que abordará la reincidencia y temas conexos desde los conocimientos científicos.

Es aquí donde la reflexión del artículo publicado en este número tiene trascendencia para las políticas públicas, entre ellas las de salud pública; el conocer por qué se reincide en el delito, la forma en que se manifiesta el delito reincidente (de igual o diferente gravedad) y la efectividad de las medidas de disuasión de nuevos delitos ${ }^{7}$, serán algunos de los temas de impacto en el futuro. La Universidad Industrial de Santander ha participado activamente en el mejoramiento del instrumento que el Instituto Nacional Penitenciario y Carcelario usa para valorar el riesgo de reincidencia (el llamado Instrumento para la Valoración Integral de Condenados) ${ }^{8}$, por lo que a futuro se considera la temática de reincidencia del delito fundamental para mejorar las condiciones de salud de quienes son privados de la libertad, así como de la sociedad colombiana en su conjunto. En ese sentido ya estamos empezando a ver los aportes que la criminología puede tener para mejorar las condiciones de salud.

\section{Referencias}

1. Larrota Castillo R, Gaviria Gómez AM, Mora Jaimes C, Arenas Rivero A. Aspectos criminogénicos de la reincidencia y su problema. Rev Univ Ind Santander Salud. 2018; 50(2): 158-165. doi: 10.18273/revsal.v50n22018006.

1. Universidad Industrial de Santander. Bucaramanga, Colombia.

Correspondencia: Alvaro Javier Idrovo. Dirección: Carrera 32 No. 29-31, Escuela de Salud Pública. Telefono: +577 6344000 ext.3123. Correo electrónico: idrovoaj@uis.edu.co 
2. Restum ZG. Public health implications of substandard correctional health care. Am J Public Health. 2005; 95(10): 1689-1691. doi: 10.2105/AJPH.2004.055053.

3. Martin MS, Colman I, Simpson AIF, McKenzie K. Mental health screening tools in correctional institutions: a systematic review. BMC Psychiatry. 2013; 13: 275. doi: 10.1186/1471-244X-13-275.

4. Idrovo AJ. Asumiendo el concepto de salud [editorial]. Rev Univ Ind Santander. Salud 2014; 46(3): 219.

5. Klevens J, Roca J. Nonviolent youth in a violent society: resilience and vulnerability in the country of Colombia. Violence Vict. 1999; 14(3): 311-322.

6. Montoya N, Restrepo A, Duque LF, Ungar M. Predicting resilient adolescents and youths: validation of a screening test in Colombia. Issues Compr Pediatr Nurs. 2011; 34(4): 167-188. doi: 10.3109/01460862.2011.619400.

7. Shepherd JP. Criminal deterrence as a public health strategy. Lancet. 2001; 358(9294): 1717-1722. doi: 10.1016/ S0140-6736(01)06716-2.

8. Instituto Nacional Penitenciario y Carcelario (INPEC). Instrumento para la valoración integral de condenados IVIC 2.0 [Documento técnico]. Bogotá: INPEC; 2017. 